\title{
Copper-graphene heterostructure for back-end-of-line compatible high-performance interconnects
}

\author{
Myungwoo Son $\mathbb{D}^{1,8 凶}$, Jaewon Jang $\mathbb{D}^{2,3,8}$, Yongsu Lee ${ }^{4}$, Jungtae Nam ${ }^{5}$, Jun Yeon Hwang ${ }^{5}$, In S. Kim $\mathbb{D}^{2,3}$, Byoung Hun Lee $\mathbb{D}^{4}$, \\ Moon-Ho $\mathrm{Ham}^{6}$ and Sang-Soo Chee (iD) ${ }^{7 \times}$
}

Here, we demonstrate the fabrication of a Cu-graphene heterostructure interconnect by the direct synthesis of graphene on a Cu interconnect with an enhanced performance. Multilayer graphene films were synthesized on $\mathrm{Cu}$ interconnect patterns using a liquid benzene or pyridine source at $400^{\circ} \mathrm{C}$ by atmospheric pressure chemical vapor deposition (APCVD). The graphene-capped Cu interconnects showed lower resistivity, higher breakdown current density, and improved reliability compared with those of pure Cu interconnects. In addition, an increase in the carrier density of graphene by doping drastically enhanced the reliability of the graphene-capped interconnect with a mean time to failure of $>10^{6} \mathrm{~s}$ at $100^{\circ} \mathrm{C}$ under a continuous DC stress of $3 \mathrm{MAcm}{ }^{-2}$. Furthermore, the graphene-capped $\mathrm{Cu}$ heterostructure exhibited enhanced electrical properties and reliability even if it was a damascene-patterned structure, which indicates compatibility with practical applications such as next-generation interconnect materials in CMOS back-end-of-line (BEOL).

npj 2D Materials and Applications (2021)5:41; https://doi.org/10.1038/s41699-021-00216-1

\section{INTRODUCTION}

As demand for smaller electronic integrated circuits (IC) continues to increase, the width and pitch of interconnects have shrunk; $\mathrm{Cu}$ interconnects suffer from size effects such as surface and grain boundary scatterings ${ }^{1-3}$. To solve this issue, carbon materials such as graphene and carbon nanotubes (CNTs), and their nanocomposites are potential materials to replace $\mathrm{Cu}$ interconnects. Among them, graphene nanoribbons (GNRs) with widths of a few nanometers are promising candidates to address the scaling issue of interconnects owing to their outstanding electrical and thermal properties and chemical stability ${ }^{4-9}$. Shao et al. demonstrated the fabrication of single-layer GNR-based interconnects ${ }^{7}$ with a high breakdown current density $\left(J_{B R}\right)$ of the order of $10^{8} \mathrm{~A} \mathrm{~cm}^{-2}$. Jiang et al. demonstrated the fabrication of intercalation-doped multilayer-GNR interconnects with improved performance and reliability ${ }^{8,9}$. However, the breakdown of the interconnect occurs at low bias owing to the low current capacity of graphene.

Graphene-capped $\mathrm{Cu}$ heterostructure (Cu/Graphene) interconnects fabricated by the direct growth of graphene on $\mathrm{Cu}$ have been studied as interconnect materials ${ }^{10-12}$. Yeh et al. demonstrated the synthesis and working of graphite/copper bishell composite interconnects with a multilayer graphene-capping layer grown by electron cyclotron resonance chemical vapor deposition (ECR-CVD) at $400^{\circ} \mathrm{C}^{10}$, which showed a $J_{\mathrm{BR}}$ of an order of $10^{8} \mathrm{~A}$ $\mathrm{cm}^{-2}$. Mehta et al. demonstrated the fabrication of grapheneencapsulated copper nanowires by plasma-enhanced CVD (PECVD) at $650^{\circ} \mathrm{C}$, which exhibited strong enhancement of electrical and thermal conductivities compared with uncoated $\mathrm{Cu} \mathrm{NWs}^{11}$. Furthermore, Li et al. demonstrated the synthesis of a graphene/Cu composite by the direct formation of graphene on
$\mathrm{Cu}$ wires at temperatures below $400^{\circ} \mathrm{C}$ via inductively coupled plasma CVD (ICP-CVD). The composite exhibits low resistivity $(\rho)$, half that of as-fabricated $\mathrm{Cu}$ wire, and high $J_{\mathrm{BR}}, 1.4$ times that of the as-fabricated $\mathrm{Cu}$ wire. It also possesses a long electromigration (EM) lifetime, 40 times that of the as-fabricated Cu wire ${ }^{12}$. These plasma-assisted CVD processes enable the synthesis of graphene at temperatures as low as $400-650^{\circ} \mathrm{C}$. However, these techniques require expensive and precise equipment, and defective graphene can form owing to damage inflicted on the graphene surface by energetic plasma ions. Therefore, there persist significant challenges for the fabrication of graphene-capped $\mathrm{Cu}$ heterostructure interconnects suitable for practical application.

Aromatic hydrocarbon molecules such as benzene and pyridine are the most favorable carbon source for the direct synthesis of high-quality graphene film at temperatures as low as $300^{\circ} \mathrm{C}$ without additional energetic plasma systems ${ }^{13,14}$. In our previous study, the synthesis of high-quality, continuous undoped and $\mathrm{N}$ doped graphene films was achieved using benzene ${ }^{13}$ and pyridine $^{14}$ via an oxygen-free APCVD at $300^{\circ} \mathrm{C}$. Using this technique, in this study, we developed graphene-capped $\mathrm{Cu}$ heterostructure interconnects by the direct synthesis of graphene on a $\mathrm{Cu}$ interconnect at $400^{\circ} \mathrm{C}$, which led to improved performance. For example, N-doped graphene-capped $\mathrm{Cu}(\mathrm{Cu} / \mathrm{N}$ graphene) interconnects exhibited $\rho$ that is $\sim 3.5 \%$ lower, a $J_{B R}$ that is $\sim 24.1 \%$ higher, and a failure time that is approximately seven times longer than those of pure $\mathrm{Cu}$ interconnects. Furthermore, we confirmed the compatibility of the graphene-capped $\mathrm{Cu}$ heterostructure with a damascene-patterned structure for practical applications.

\footnotetext{
${ }^{1}$ Artificial Intelligence and Energy Research Center, Korea Photonics Technology Institute (KOPTI), Cheomdanbencheo-ro 108 beon-gil 9, Buk-gu, Gwangju 61007, Republic of Korea. ${ }^{2}$ Global Desalination Research Center, Gwangju Institute of Science and Technology (GIST), 123 Cheomdangwagi-ro, Buk-gu, Gwangju 61005, Republic of Korea. ${ }^{3}$ School of Earth Sciences and Environmental Engineering, Gwangju Institute of Science and Technology (GIST), 123 Cheomdangwagi-ro, Buk-gu, Gwangju 61005, Republic of Korea. ${ }^{4}$ Department of Electrical Engineering, Pohang University of Science and Technology (POSTECH), Cheongam-ro 77, Nam-gu, Pohang, Gyeongbuk 37673, Republic of Korea. ${ }^{5}$ Institute of Advanced Composites Materials, Korea Institute of Science and Technology (KIST), 92 Chudong-ro, Eunha-ri, Bongdong-eup, Wanju-gun, Jeonbuk 55324, Republic of Korea. ${ }^{6}$ School of Materials Science and Engineering, Gwangju Institute of Science and Technology, 123 Cheomdangwagi-ro, Buk-gu, Gwangju 61005, Republic of Korea. ${ }^{7}$ Nanomaterials and Nanotechnology Center, Korea Institute of Ceramic Engineering and Technology (KICET), 101 Soho-ro, Jinju-si, Gyeongsangnam-do 52851, Republic of Korea. ${ }^{8}$ These authors contributed equally: Myungwoo Son and Jaewon Jang. ${ }^{凶}$ email: mwson@kopti.re.kr; sschee@kicet.re.kr
} 


\section{RESULTS}

Fabrication of $\mathrm{Cu} / \mathrm{Graphene}$ heterostructure interconnects We implemented oxygen-free APCVD at $400^{\circ} \mathrm{C}$ using benzene and pyridine carbon sources to directly integrate multilayer graphene film into $\mathrm{Cu}$ interconnects. The types of interconnects with their components and synthesis conditions of graphene have been described (Supplementary Fig. 1) ${ }^{13,14}$. Optical micrograph and scanning electron microscopy (SEM) images show that the $\mathrm{Cu}$ interconnect remained physically intact without any change in surface morphology (e.g., pore or dewetting regions), because the low-temperature process prevented thermal damage to the $\mathrm{Cu}$ (Fig. 1a and Supplementary Fig. 2). In addition, Cu grain size in interconnects was expanded by thermal annealing during the graphene synthesis process, which improved the electrical properties of the $\mathrm{Cu}$ interconnect (Supplementary Fig. 2). The schematic in Fig. 1a shows the Cu-graphene heterostructure formed by low-temperature CVD. Graphitic films on the surfaces of the $\mathrm{Cu}$ interconnect were observed in high-resolution transmission electron microscopy (HRTEM) images (Fig. 1b). Uniform multilayer graphene films were synthesized on the top, left, and right sides of the $\mathrm{Cu}$ interconnect (Fig. 1b). The thickness of the graphene films grown for 120 min was $\sim 7 \mathrm{~nm}$ with the number of layers ranging from 20 to 22 . Hence, this low-temperature CVD process is suitable for the fabrication of Cu-graphene heterostructure interconnects.

Representative graphene peaks such as the $G$ and 2D bands were observed in the Raman spectra of the $\mathrm{Cu} / \mathrm{Graphene}$ and $\mathrm{Cu}$ /
$\mathrm{N}$-graphene interconnects. Furthermore, an $I_{2 \mathrm{D}} / \mathrm{I}_{\mathrm{G}}$ of less than 0.5 with a broad $2 \mathrm{D}$ peak depicted the formation of a multilayer graphene film, which is consistent with the TEM images (Fig. 1C). The full-width at half-maximum (FWHM) of the 2D peak of undoped graphene and $\mathrm{N}$-doped graphene synthesized using APCVD, which indicate a randomly rotated structure of $c$-axis, were $\sim 62.9$ and $\sim 64.3$, respectively. These values are lower than those of a graphitic layer grown via ECR-CVD $(\sim 90.9)^{10}$, graphene via PECVD $(\sim 71.1)^{11}$, and amorphous carbon via ICP-CVD $(\sim 153.5)^{12}$, which demonstrates the formation of higher crystalline graphene films layer on $\mathrm{Cu}$ interconnects (Supplementary Fig. 3) ${ }^{15}$. By contrast, no graphene was detected in the as-fabricated $\mathrm{Cu}$ and annealed $\mathrm{Cu}$ interconnects, and the $\mathrm{SiO}_{2}$ region of substrate after graphene synthesis. This suggests the possibility that graphitic film formed during annealing can be excluded; it also suggests that annealing is only helpful in the synthesis of a uniform multilayer graphene film and in the improvement of the electrical properties of the $\mathrm{Cu}$ interconnect by increasing the grain size of the Cu surface ${ }^{16}$. Hence, multilayer graphene films were selectively synthesized on $\mathrm{Cu}$ interconnect surfaces in the growth step of CVD at $400^{\circ} \mathrm{C}$ (Fig. 1C). In addition, because the integration of CVD-grown graphene films is used in this study, uniform, inchscale Cu-graphene heterostructure interconnects can be fabricated on one substrate. The Raman spectra of graphene measured in randomly selected $\mathrm{Cu}$ interconnects in nine different regions of a wafer (area of 1 inch $^{2}$ ) exhibited excellent uniformity, which is
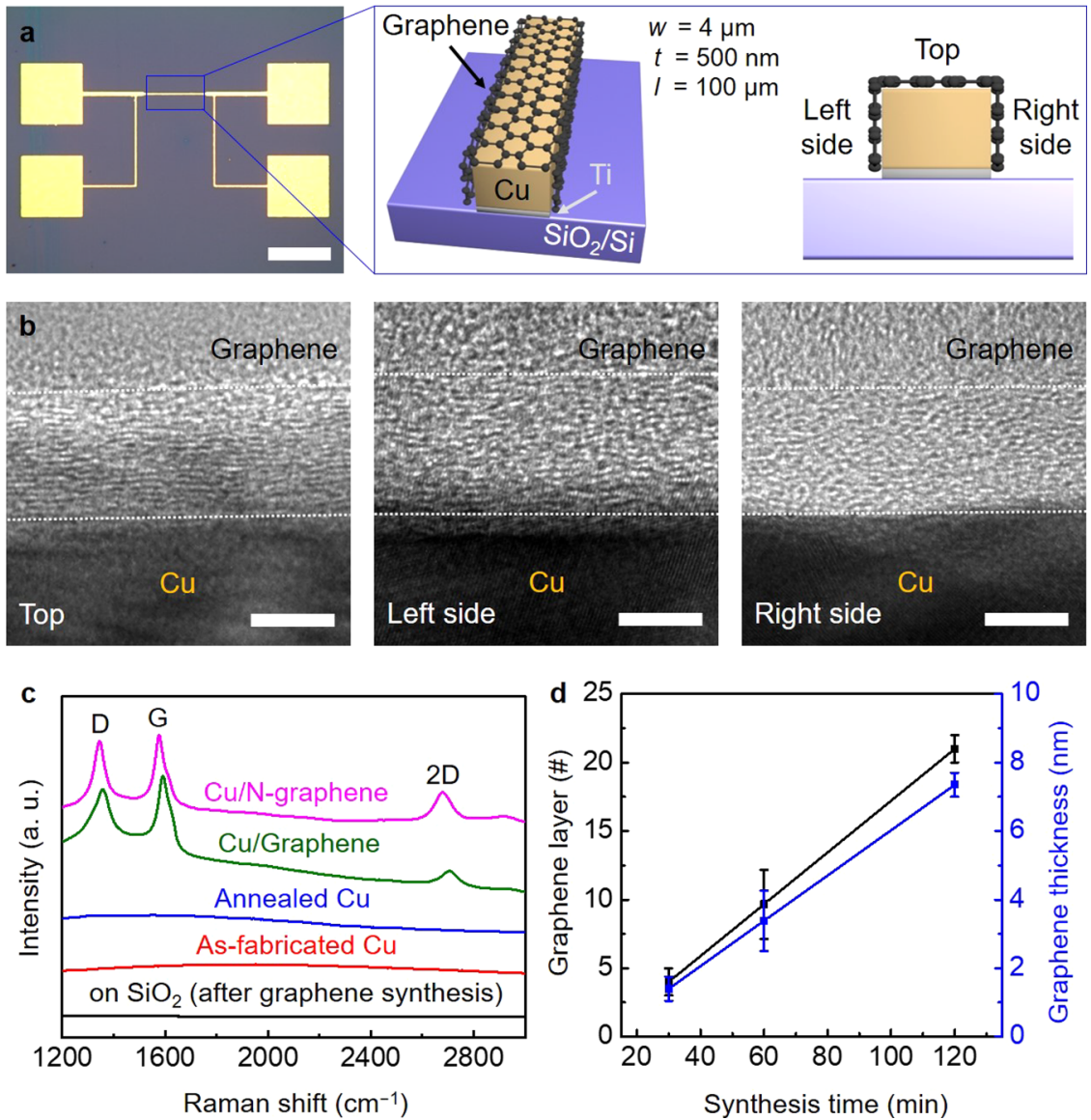

Fig. 1 Characteristics of graphene-capped $\mathrm{Cu}$ interconnects. a Optical and schematic images of graphene-capped $\mathrm{Cu}$ interconnects fabricated by direct synthesis of graphene on $\mathrm{Cu}$ interconnects via APCVD using benzene and pyridine at $400{ }^{\circ} \mathrm{C}$. $\mathbf{b}$ HRTEM images of graphene synthesized on the top, left, and right sides of the $\mathrm{Cu}$ interconnect for $120 \mathrm{~min}$. c Raman spectra of as-deposited Cu, annealed Cu, undoped and $\mathrm{N}$-doped graphene-capped Cu interconnects measured on Cu surfaces and $\mathrm{SiO}_{2}$ of substrate after graphene synthesis. $\mathbf{d}$ The number and thickness of graphene synthesized on the $\mathrm{Cu}$ interconnect using benzene estimated TEM images of Supplementary Fig. 5. Scale bars, $100 \mu \mathrm{m}$ in a, $5 \mathrm{~nm}$ in $\mathbf{b}$. 

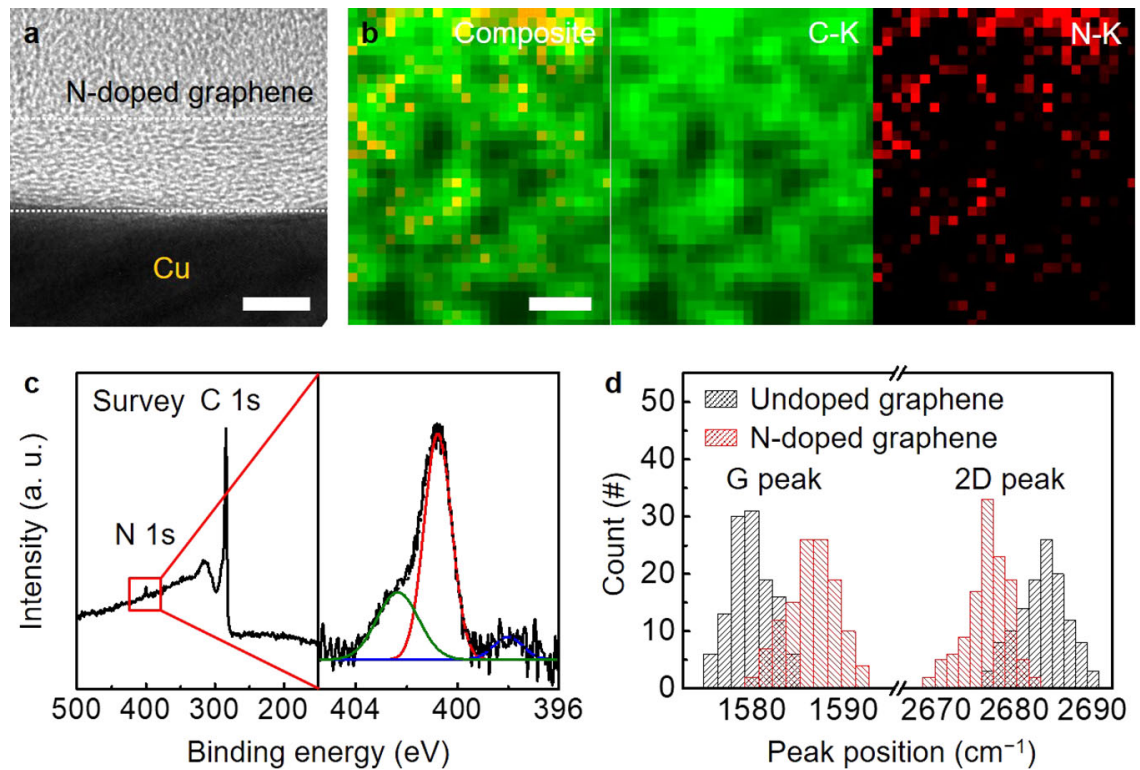

Fig. 2 Characteristics of the $\mathbf{N}$-doped graphene on $\mathbf{C u}$ interconnects. a HRTEM image, b EELS mapping images, and $\mathbf{c}$ XPS spectra of Ndoped graphene synthesized on the $\mathrm{Cu}$ interconnect using pyridine by APCVD at $400^{\circ} \mathrm{C}$. $\mathbf{d} \mathrm{G}$ and $2 \mathrm{D}$ peak position distributions of undoped and $\mathrm{N}$-doped graphene estimated from Raman mapping images of Supplementary Fig. 8. Scale bars, $5 \mathrm{~nm}$ in $\mathbf{a}$ and $\mathbf{b}$.

significant for realizing large-area Cu-graphene-based interconnects (Supplementary Fig. 4).

Graphene synthesis on $\mathrm{Cu}$ interconnects via APCVD enables the thickness control of the graphitic coating layer as a function of the synthesis time ${ }^{10,17}$. For a short synthesis time of $30 \mathrm{~min}$, a thin graphene film of $\sim 1.5 \mathrm{~nm}$ was formed on the $\mathrm{Cu}$ interconnects and the thickness of the graphitic film proportionally increased to $\sim 7.35 \mathrm{~nm}$ as the synthesis time increased. The formation of continuous multilayer graphene films ranging from 4 to 21 layers grown for 30-120 min was observed in TEM images (Fig. 1d and Supplementary Fig. 5). Generally, the synthesis of graphene on $\mathrm{Cu}$ foil via LPCVD results in the formation of a monolayer graphene film as a result of the self-limiting effect of $\mathrm{Cu}$ induced by the low solubility of carbon ${ }^{18}$. By contrast, for $\mathrm{Cu}$ interconnects fabricated by sputtering and annealing, it is possible for numerous nuclei of graphene to be initiated and a larger amount of carbon atoms to be absorbed on polycrystalline $\mathrm{Cu}$, leading to the formation of multilayer graphene ${ }^{19}$.

To compare the crystallinity of $\mathrm{Cu}, \mathrm{X}$-ray diffraction (XRD) patterns of the $\mathrm{Cu}$ foil and $\mathrm{Cu}$ interconnect were acquired. XRD revealed only a majority (111) grain orientation in the $\mathrm{Cu}$ foil, which may be responsible for the formation of the single-layer graphene owing to the low solubility of carbon in $\mathrm{Cu}^{16}$. Meanwhile, the XRD patterns of polycrystalline $\mathrm{Cu}$ interconnect show major (111) and minor (200) grain orientations (Supplementary Fig. 6a). The HRTEM image of $\mathrm{Cu}$ foil reveals the presence of (111) lattice fringes with no grain boundaries. In addition, in the accompanying selected area electron diffraction (SAED) patterns, the ordered array of the clear bright diffraction spots indicates that the $\mathrm{Cu}$ foil is a single crystal with a face-centered cubic (FCC) structure (Supplementary Fig. 6b). By contrast, HRTEM image and SAED patterns of the $\mathrm{Cu}$ interconnect show the different orientations of atomic arrangements with grain boundaries and mix-ordered patterns, indicating polycrystalline $\mathrm{Cu}$ with numerous defects such as point defects and grain boundaries, which act as nucleation sites for graphene, owing to which multilayer graphene films were achieved (Supplementary Fig. 6c).

Furthermore, we synthesized an N-doped multilayer graphene film using pyridine at $400^{\circ} \mathrm{C}$ to improve the electrical properties of interconnects by the doping effect. For comparison with the undoped-graphene-capping layer, the $\mathrm{N}$-doped graphene film was synthesized with a similar thickness of graphene being grown on $\mathrm{Cu} / \mathrm{Graphene}$ interconnects. In the TEM image, the thickness of the $\mathrm{N}$-doped graphene film was confirmed to be $\sim 7 \mathrm{~nm}$ with the number of layers being 20 (Fig. 2a). In addition, the presence of nitrogen was observed in electron energy loss spectroscopy (EELS) mapping. Red spots denoting nitrogen atoms are distributed over the entire graphene film, demonstrating the uniform doping of nitrogen atoms in graphene. The amount of nitrogen was estimated to be $\sim 2.32$ at.\% based on atomic analysis of the EELS mapping data (Fig. 2b).

X-ray photoelectron spectroscopy (XPS) of the N-doped graphene was performed to detect the nitrogen in graphene. The survey spectrum of $\mathrm{N}$-doped graphene showed carbon and nitrogen bonding peaks located at approximately 285 and $400 \mathrm{eV}$, respectively. The $\mathrm{N}$ 1s spectrum showed three nitrogen bonding components located at 398.0 (blue line), 400.9 (red line), and $402.5 \mathrm{eV}$ (olive line), corresponding to pyridinic, graphitic, and

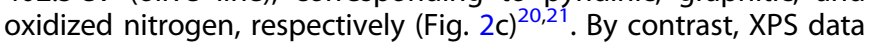
obtained for the undoped graphene grown using benzene showed carbon bonding peaks without any nitrogen (Supplementary Fig. 7). Therefore, the presence of nitrogen in graphene obtained from pyridine was confirmed. XPS quantitative analysis reveals that the amount of nitrogen in graphene was $~ 2.11$ at.\%, consistent with the EELS results. Raman spectroscopy of the pyridine-derived graphene was conducted to confirm the nitrogen doping effect in comparison with the undoped graphene because the positions of representative peaks such as $G$ and 2D bands in Raman spectra shifted owing to electron or hole doping ${ }^{22}$. Raman mapping analysis of pyridine-derived graphene film exhibited a $G$ peak with a higher wavenumber and a 2D peak with a lower wavenumber as compared with those of undoped graphene, which is consistent with previous studies (Fig. 2d and Supplementary Fig. 8). Hence, the formation of a large-area, N-doped multilayer graphene film was demonstrated.

\section{Electrical properties of graphene-capped $\mathrm{Cu}$ interconnects}

The performance of graphene-capped $\mathrm{Cu}$ interconnects fabricated by the direct growth of graphene on $\mathrm{Cu}$ interconnects at $400^{\circ} \mathrm{C}$ via APCVD was characterized and compared with $\mathrm{Si}_{3} \mathrm{~N}_{4}$-capped $\mathrm{Cu}$ interconnects $\left(\mathrm{Cu} / \mathrm{Si}_{3} \mathrm{~N}_{4}\right)$ without graphene to demonstrate the advantages of graphene. The annealed $\mathrm{Cu}$ interconnects showed 

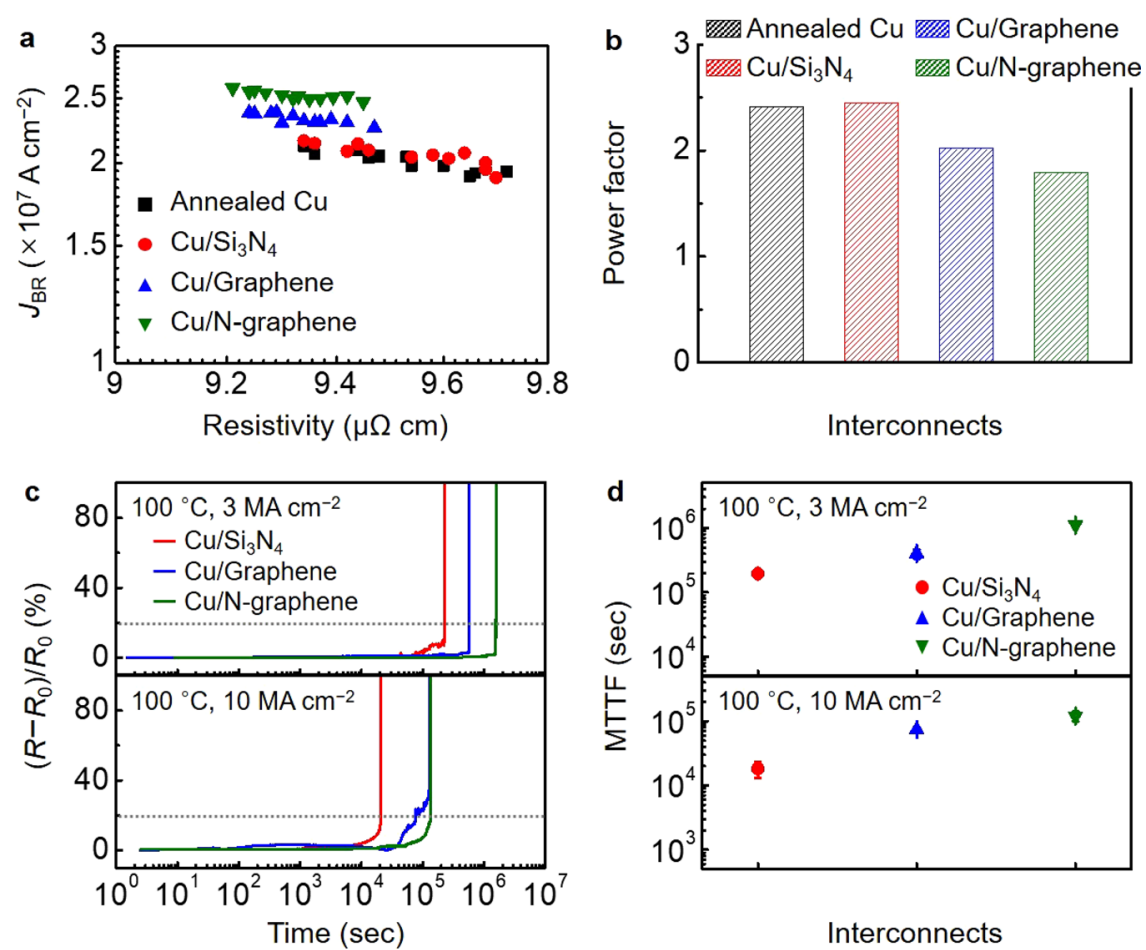

Fig. 3 The interconnect performance of graphene-capped $\mathbf{C u}$ heterostructures. a $J_{B R}$ vs $\rho$ plots $\mathbf{b}$ power factors of annealed $\mathrm{Cu}, \mathrm{Cu} / \mathrm{Si}_{3} \mathrm{~N}_{4}$ $\mathrm{Cu} / \mathrm{Graphene}$ and $\mathrm{Cu} / \mathrm{N}$-graphene interconnects. Power factors are calculated from Log $\left(J_{\mathrm{BR}}\right)$ vs Log $(\rho)$ plots of Supplementary Fig. 10 . c $\left(R-R_{0}\right) / R_{0}$ vs time curve and $\mathbf{d}$ failure time of $\mathrm{Cu} / \mathrm{Si}_{3} \mathrm{~N}_{4}, \mathrm{Cu} / \mathrm{Graphene}$ and $\mathrm{Cu} / \mathrm{N}$-graphene interconnects measured at $100{ }^{\circ} \mathrm{C}$ under 3 and $10 \mathrm{MA} \mathrm{cm}^{-2}$.

a resistivity $(\rho)$ of $9.58 \pm 0.12 \mu \Omega \mathrm{cm}$ and breakdown current density $\left(J_{\mathrm{BR}}\right)$ of $20.2 \pm 0.7 \mathrm{MA} \mathrm{cm}^{-2}$, which were superior to those of the as-fabricated $\mathrm{Cu}$ interconnect. The primary reason for this was the decrease in grain boundary scattering owing to increased grain size (Supplementary Fig. 2) ${ }^{11,23}$. The integration of lowresistivity graphene on a $\mathrm{Cu}$ interconnect (Cu/Graphene) enhanced its performance. In addition, the $J_{\mathrm{BR}}$ of the $\mathrm{Cu} / \mathrm{Graphene}$ interconnect increased with the thickness of graphene and saturated up to $\sim 7 \mathrm{~nm}$ (Supplementary Fig. 9) ${ }^{10}$. A noticeable performance improvement was observed wherein $\rho$ was reduced to $9.29 \pm 0.07 \mu \Omega \mathrm{cm}$ and $J_{B R}$ increased up to $23.3 \pm 0.4 \mathrm{MA} \mathrm{cm}^{-2}$ for the 7-nm-thick graphene heterostructure $\mathrm{Cu}$ interconnects (Fig. 3a and Supplementary Fig. 10a). By contrast, the insulating capping layer did not influence the electrical properties of $\mathrm{Cu}$ interconnects significantly. The $\mathrm{Cu} / \mathrm{Si}_{3} \mathrm{~N}_{4}$ interconnects showed a $\rho$ of $9.62 \pm 0.13 \mu \Omega \mathrm{cm}$ and a $J_{\mathrm{BR}}$ of $20.5 \pm 0.8 \mathrm{MA} \mathrm{cm}^{-2}$, similar to those of the $\mathrm{Cu}$ interconnects (Fig. 3a and Supplementary Fig. 10a). This demonstrated that the integration of a metallic graphene-capping layer with interconnects using the direct synthesis of graphene provides low-resistance and fast-current pathways as well as improvement of Cu crystal structure, leading to performance enhancement achieved in the form of a $3.1 \%$ increase in $\rho$ and $14.8 \%$ increase in $J_{\mathrm{BR}}$ as compared with the pure Cu counterpart ${ }^{10,11,24}$.

The performance of graphene-capped $\mathrm{Cu}$ interconnects was further improved by doping with graphene. Pyridine-derived $\mathrm{N}$ doped graphene exhibits a lower resistivity than that of benzenederived undoped graphene because of a higher charge carrier density in graphene induced by additional electrons ${ }^{14,17}$. Hence, $\mathrm{Cu} / \mathrm{N}$-graphene interconnects showed the lowest $\rho$ (9.25 \pm $0.07 \mu \Omega \mathrm{cm})$ and highest $J_{\mathrm{BR}}\left(25.2 \pm 0.4 \mathrm{MA} \mathrm{cm}^{-2}\right)$, indicating an improvement of $3.5 \%$ in $\rho$ and $24.1 \%$ in $J_{B R}$ as compared with those of the pure $\mathrm{Cu}$ interconnect (Fig. 3a and Supplementary Fig. 10).
The enhanced $J_{\mathrm{BR}}$ of the graphene-capped $\mathrm{Cu}$ interconnects may be due to the graphene, which suppresses the EM and temperature increase in the $\mathrm{Cu}$ of heterostructure interconnects ${ }^{25}$. SEM images show the void and breakdown points of the interconnects after electrical breakdown (Supplementary Fig. 11). Larger voids were observed in the graphene-capped $\mathrm{Cu}$ interconnects compared with those in the annealed $\mathrm{Cu}$ and $\mathrm{Cu} / \mathrm{Si}_{3} \mathrm{~N}_{4}$ interconnects. The breakdown of interconnects occurs as a result of elevated temperature produced by Joule heating. Hence, the higher Joule heat in $\mathrm{Cu} / \mathrm{Graphene}$ and $\mathrm{Cu} / \mathrm{N}$-graphene interconnects at higher $J_{B R}$ induced a greater breakdown void. In addition, the breakdown points of the $\mathrm{Cu} / \mathrm{Graphene}$ and $\mathrm{Cu} / \mathrm{N}$-graphene interconnects were shifted farther away from the electron injection contact electrode than those of the annealed $\mathrm{Cu}$ and the $\mathrm{Cu} / \mathrm{Si}_{3} \mathrm{~N}_{4}$ interconnects. This demonstrates that the graphenecapping layer mitigated the EM of $\mathrm{Cu}$ owing to an increased activation energy; these effects will be discussed later ${ }^{26,27}$.

To gain deeper insight into the physical role of graphene in the improvement of electrical properties of graphene-capped $\mathrm{Cu}$ heterostructure interconnects, we calculated the resistivity of undoped and $\mathrm{N}$-doped graphene film directly synthesized on $\mathrm{Cu}$ interconnect. Given that each graphene layer has uniform resistance and is electrically connected to the underlying $\mathrm{Cu}$ interconnect in parallel, the total resistivity of the heterostructure can be obtained by ${ }^{16}$

$$
\begin{aligned}
& w_{(\mathrm{Cu} / \text { Graphene })} \cdot t_{(\mathrm{Cu} / \mathrm{Graphene})} / \rho_{(\mathrm{Cu} / \mathrm{Graphene})}=w_{(\mathrm{Cu})} \cdot t_{(\mathrm{Cu})} / \rho_{(\mathrm{Cu})} \\
& \quad+\left(w_{(\mathrm{Cu})} \cdot t_{\left(\mathrm{Graphene \_ region} 1\right)}+t_{(\mathrm{Cu})} \cdot t_{(\text {Graphene_region } 2)}\right. \\
& \left.\quad+t_{(\mathrm{Cu})} \cdot w_{(\mathrm{Cu})} \cdot t_{(\text {Graphene_region } 3)}\right) / \rho_{(\text {Graphene })}
\end{aligned}
$$

where $w_{(\mathrm{Cu} / \text { Graphene) }}=w_{\text {(Graphene_region 2) }}+w_{\text {(Graphene_region 3) }}$ is the total width and $t_{(\mathrm{Cu} / \mathrm{Graphene})}=t_{(\mathrm{Cu})}+t_{(\mathrm{Graphen} \text { _region 1) }}$ is the total thickness of the heterostructure. Then, the total cross-sectional area of the graphene overlayer is given by $w_{(\mathrm{Cu})} t_{(\mathrm{Graphene})}+$ $2 t_{(\mathrm{Cu})} t_{\text {(Graphene) }}$ because the thickness of graphene grown on the 

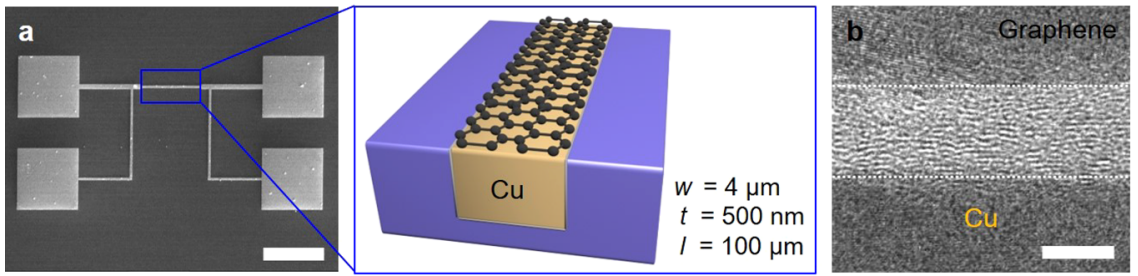

C
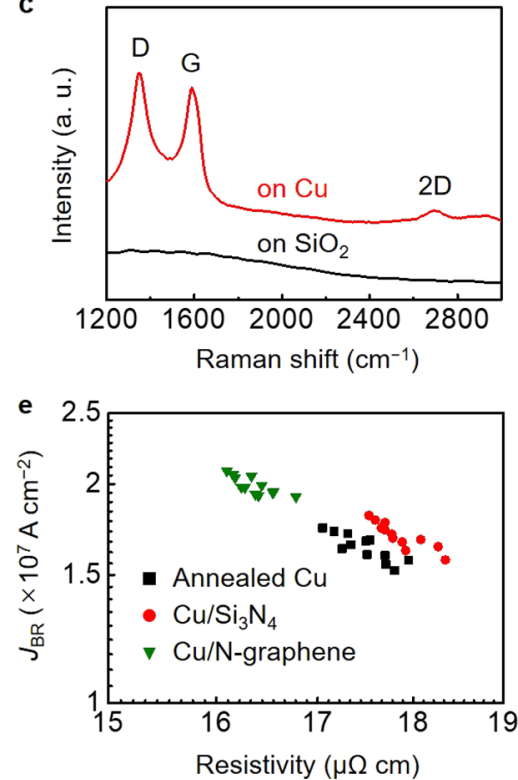
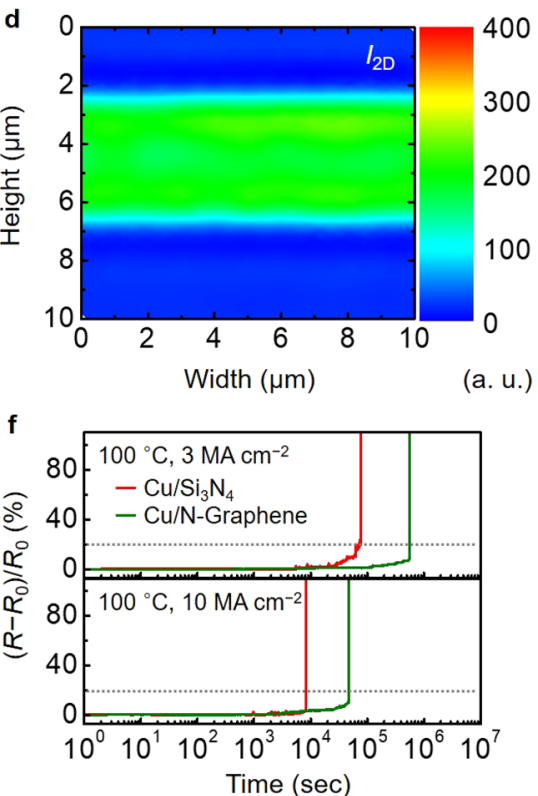

Fig. 4 Characteristics of the damascene-patterned Cu-graphene interconnects. a SEM and schematic images of Cu/N-graphene interconnect with damascene-patterned structure. b HRTEM image of N-doped graphene synthesized on the damascene-patterned Cu interconnect using pyridine by APCVD at $400^{\circ} \mathrm{C}$. c Raman spectra of damascene-patterned $\mathrm{Cu}$ interconnects measured on $\mathrm{Cu}$ surface and SiO ${ }_{2}$ of substrate after graphene synthesis d Raman mapping image of $\mathrm{N}$-doped graphene synthesized on damascene-patterned Cu interconnect.

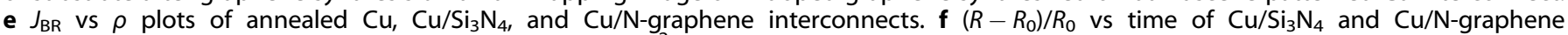
interconnects measured at $100^{\circ} \mathrm{C}$ under 3 and $10 \mathrm{MA} \mathrm{cm}^{-2}$. Scale bars, $100 \mu \mathrm{m}$ in $\mathbf{a}, 5 \mathrm{~nm}$ in $\mathbf{b}$.

entire Cu surface is almost uniform. Taking the 500-nm-width test $\mathrm{Cu}$ interconnects with 7-nm-thick graphene-capping layer as an example, where $\rho_{(\mathrm{Cu})}=9.58 \mu \Omega \mathrm{cm}, \rho_{\text {(Cu/Graphene) }}=9.29 \mu \Omega \mathrm{cm}$, and $\rho_{(\mathrm{Cu} / \mathrm{N} \text {-graphene) }}=9.25 \mu \Omega \mathrm{cm}$ were acquired from measurements, the resistivity values of undoped and $\mathrm{N}$-doped graphene layers were calculated to be 3.4 and $3.1 \mu \Omega \mathrm{cm}$, respectively. This indicates that the graphene-capping layer strongly influences the electrical properties of the Cu-graphene heterostructure because $\rho_{\text {(Cu/Graphene) }}$ is less than $\rho_{(\mathrm{Cu})}$.

In addition, the power factor of interconnects was calculated to describe the relationship between the breakdown current density and resistivity: ${ }^{10,28}$

$J_{\max }=A \rho^{-n}$

where $A$ is a fitting parameter and $n$ is a power factor. A fit to the power law yielded $n$ values of 2.41 and 2.45 for annealed $\mathrm{Cu}$ and $\mathrm{Cu} / \mathrm{Si}_{3} \mathrm{~N}_{4}$, respectively. Surface scattering at the $\mathrm{Cu} / \mathrm{Si}_{3} \mathrm{~N}_{4}$ interface can lead to a significant degradation of interconnect performance. However, the resistivity, breakdown current density, and power factor of $\mathrm{Cu} / \mathrm{Si}_{3} \mathrm{~N}_{4}$ interconnects are similar to those of $\mathrm{Cu}$ interconnects, indicating that the $\mathrm{Si}_{3} \mathrm{~N}_{4}$ capping layer does not affect the electrical properties of $\mathrm{Cu}$ interconnects ${ }^{29}$. By contrast, the graphene-capped $\mathrm{Cu}$ interconnects showed lower $n$ values of 2.02 (Cu/Graphene) and 1.79 (Cu/N-graphene), indicating that the graphene-capping layer acts as the dominant current pathway in $\mathrm{Cu}$-graphene heterostructures and, hence, enhances the performance of the interconnect (Fig. 3b and Supplementary Fig. 10b).

Thus, we confirmed the reliability of graphene-capped $\mathrm{Cu}$ interconnects by measuring the mean time to failure (MTTF) at $100^{\circ} \mathrm{C}$ under a continuous DC stress of 3 and $10 \mathrm{MA} \mathrm{cm}^{-2}$ and compared it with that of the $\mathrm{Cu} / \mathrm{Si}_{3} \mathrm{~N}_{4}$ interconnects because pure $\mathrm{Cu}$ interconnects without an oxygen barrier are readily oxidized above $100^{\circ} \mathrm{C}$ (Supplementary Fig. 12) ${ }^{30}$. The failure times for the $\mathrm{Cu} /$ $\mathrm{Si}_{3} \mathrm{~N}_{4}$ interconnects were $\sim 200,000 \mathrm{~s}\left(3 \mathrm{MA} \mathrm{cm}^{-2}\right)$ and $\sim 18,000 \mathrm{~s}$ $\left(10 \mathrm{MA} \mathrm{cm}^{-2}\right)$ because EM in $\mathrm{Cu}$ creates voids and increases the resistance of interconnects. By contrast, the undoped graphenecapped $\mathrm{Cu}$ interconnects had increased failure times of $\sim 400,000 \mathrm{~s}$ $\left(3 \mathrm{MA} \mathrm{cm}^{-2}\right)$ and $\sim 74,000 \mathrm{~s}\left(10 \mathrm{MA} \mathrm{cm}^{-2}\right)$. Furthermore, N-doped graphene-capped $\mathrm{Cu}$ interconnects showed enhanced failure times of $\sim 1,390,000 \mathrm{~s}\left(3 \mathrm{MA} \mathrm{cm}^{-2}\right.$ ) and $\sim 120,000 \mathrm{~s}\left(10 \mathrm{MA} \mathrm{cm}^{-2}\right.$ ) (Fig. 3c, d). The graphene-capping on the $\mathrm{Cu}$ interconnects leads to lower electrical resistivity and higher thermal conductivity in the heterostructure interconnect owing to the high heat dissipation of graphene ${ }^{31,32}$. In addition, C-Cu binding at the surface of the interconnect results in more stable and unmoved $\mathrm{Cu}$ atoms against electrical stress. Furthermore, an increase in the carrier density in graphene by doping drastically enhances the reliability of $\mathrm{Cu} / \mathrm{N}$ graphene interconnects with a failure time of $>10^{6} \mathrm{~s}$ under $100^{\circ} \mathrm{C}$ and $3 \mathrm{MA} \mathrm{cm}^{-2} \mathrm{DC}$ stress. Hence, the EM is significantly mitigated by integrating the high conducting graphene layer on $\mathrm{Cu}$, leading to enhanced reliability and thermal stability of the interconnects ${ }^{12}$.

In addition, we implemented the fabrication of a $\mathrm{Cu} / \mathrm{N}$ graphene interconnect with a damascene-patterned structure for practical applications ${ }^{1}$. A single damascene process was used to form $\mathrm{Cu}$ interconnect patterns to test the synthesis of the graphene (see Methods section for details). A selectively grown graphene-capping layer on a flat $\mathrm{Cu}$ surface was obtained without any physical changes (Fig. 4a-d). HRTEM image shows that the N- 
doped graphene film was synthesized on the damascene patterned-Cu interconnect surface. The thickness of the graphene film was approximately $6.5 \mathrm{~nm}$ with 18 layers (Fig. 4b). In addition, Raman spectra and mapping image indicate that graphene was successfully synthesized on top of the $\mathrm{Cu}$ interconnects. In contrast to the detection of no graphene on the $\mathrm{SiO}_{2}$, the 2D peak clearly demonstrates that crystalline peaks were only in the $\mathrm{Cu}$ regions (Fig. 4c, d). The improvement of the interconnect performance by the graphene-capping layer in the damascenepatterned structure was confirmed from a decrease in $\rho$ and an increase in $J_{B R}$ and by the failure time. The $\mathrm{Cu} / \mathrm{N}$-graphene interconnect showed a $\rho$ of $16.4 \pm 0.2 \mu \Omega \mathrm{cm}$ and $J_{B R}$ of $19.9 \pm$ $0.6 \mathrm{MA} \mathrm{cm}^{-2}$, corresponding to an improvement of $4.1 \%$ and $21.3 \%$ over the pure $\mathrm{Cu}$ interconnect owing to a lower power factor (1.83) (Fig. 4e and Supplementary Fig. 13). In addition, the lifetimes of $\mathrm{Cu} / \mathrm{N}$-graphene interconnects as per the MTTF measurement were $\sim 600,000 \mathrm{~s} \quad\left(3 \mathrm{MA} \mathrm{cm}^{-2}\right)$ and $\sim 47,000 \mathrm{~s}$ $\left(10 \mathrm{MA} \mathrm{cm}^{-2}\right)$ longer than the $\sim 73,000 \mathrm{~s}\left(3 \mathrm{MA} \mathrm{cm}^{-2}\right)$ and $\sim 8300 \mathrm{~s}\left(10 \mathrm{MA} \mathrm{cm}^{-2}\right)$ for $\mathrm{Cu} / \mathrm{Si}_{3} \mathrm{~N}_{4}$ (Fig. 4f). Thus, enhanced electrical properties and reliability were obtained by a graphenecapping layer even for a damascene-patterned structure.

\section{DISCUSSION}

We demonstrated the feasibility and benefits of graphene-capped $\mathrm{Cu}$ heterostructure interconnects by the direct synthesis of graphene films on $\mathrm{Cu}$ interconnects via APCVD at $400^{\circ} \mathrm{C}$ while keeping the underlying $\mathrm{Cu}$ interconnect intact. The performance of the graphene-capped $\mathrm{Cu}$ interconnects in terms of resistivity, breakdown current density, and MTTF was enhanced as compared with those of pure $\mathrm{Cu}$ interconnects. Furthermore, the compatibility of the graphene-capped $\mathrm{Cu}$ heterostructure with the damascene-patterned structure was confirmed. This study is a significant step toward the direct fabrication of graphene-capped $\mathrm{Cu}$ interconnect during the manufacturing of future advanced interconnects for practical applications such as CMOS back-endof-line (BEOL).

\section{METHODS}

\section{Direct growth of graphene on $\mathrm{Cu}$ interconnects via APCVD}

$\mathrm{Cu}$ interconnect patterns, were fabricated on $\mathrm{SiO}_{2} / \mathrm{Si}$ substrates using photolithography followed by $\mathrm{Cu}$ sputtering. The width $(w)$, thickness $(t)$, and length $(I)$ of the $\mathrm{Cu}$ interconnect line are $4 \mu \mathrm{m}, 500 \mathrm{~nm}$, and $100 \mu \mathrm{m}$, respectively. Then, it was loaded into the hot center of a quartz tube. Prior to graphene growth, the quartz tube was pumped down to $\sim 10^{-4}$ Torr and then purged with argon. This process was repeated five times to flush the air contained in the quartz tube (residual oxygen concentration of $0 \%$ ). After $200 \mathrm{sccm}$ of Ar gas was supplied into the quartz tube, the pump was switched off, and the quartz tube was kept at ambient pressure. To increase the $\mathrm{Cu}$ grain size and ensure the removal of native oxide and a smooth $\mathrm{Cu}$ surface, the $\mathrm{Cu}$ interconnect was annealed at $750^{\circ} \mathrm{C}$ for $30 \mathrm{~min}$ under a $100 \mathrm{sccm}$ of hydrogen atmosphere and was subsequently rapidly cooled down to the desired synthesis temperature $\left(400^{\circ} \mathrm{C}\right)$. Once the desired temperature was reached, the flow rate of hydrogen gas was changed to $50 \mathrm{sccm}$ while the carbon source was introduced by bubbling liquid benzene ( $\geq 99.9 \%$, Sigma-Aldrich) at room temperature. The carbon source was supplied to the quartz tube with $150 \mathrm{sccm}$ of argon flow (carrier gas) for 30-120 min, producing a graphene layer on $\mathrm{Cu}$ interconnects. The graphene growth was completed by stopping the supply of benzene, and the furnace was subsequently cooled to room temperature while hydrogen and argon (50 and $500 \mathrm{sccm}$, respectively) continued flowing without supplying benzene. Further, Cu/N-graphene interconnects were fabricated using a pyridine carbon source $(\geq 99.9 \%$, Sigma-Aldrich) via APCVD. The multilayer $\mathrm{N}$-doped graphene films were directly grown onto $\mathrm{Cu}$ interconnects at $400{ }^{\circ} \mathrm{C}$ with $150 \mathrm{sccm}$ of hydrogen gas and $200 \mathrm{sccm}$ of argon flow (carrier gas) for $180 \mathrm{~min}$ after annealing process which is the same for the fabrication process of $\mathrm{Cu} / \mathrm{Graphene}$ interconnect. For comparison, annealed $\mathrm{Cu}$ interconnects was fabricated at $400^{\circ} \mathrm{C}$ by APCVD without carbon source. The information of annealed $\mathrm{Cu}$ and $\mathrm{Cu} / \mathrm{Graphene}$ and $\mathrm{Cu} / \mathrm{N}$-graphene interconnects was summarized in Supplementary Fig. 1. In order to compare oxygen barrier characteristic, annealed $\mathrm{Cu}$ interconnects without and with $\mathrm{Si}_{3} \mathrm{~N}_{4}$ capping layer was fabricated. $\mathrm{A} \mathrm{Si}_{3} \mathrm{~N}_{4}$ deposition was carried out at a background pressure of $1 \times 10^{-6}$ Torr. A 30 -nm-thick $\mathrm{Si}_{3} \mathrm{~N}_{4}$ thin film was deposited using PECVD at $300^{\circ} \mathrm{C}$ with $400 \mathrm{sccm}$ of $\mathrm{SiH}_{4}, 20 \mathrm{sccm}$ of $\mathrm{NH}_{3}$, and $600 \mathrm{sccm}$ of $\mathrm{N}_{2}$ flow under a working pressure of 650 mTorr and an RF power of $30 \mathrm{~W}$.

For practical application, graphene-capped $\mathrm{Cu}$ interconnects with the damascene patterned structure were tested. The dielectric layer was deposited on the silicon substrate. The trench was formed by patterning using photolithography followed etching techniques. After deposition of $\mathrm{TaN} / \mathrm{Ta}(15 / 10 \mathrm{~nm})$ layer as a diffusion barrier, the trench was filled by sputtering of $\mathrm{Cu}$. As the excess $\mathrm{Cu}$ is removed by a chemical mechanical polishing (CMP) damascene-patterned Cu interconnect was formed. Its $w, t$, and $I$ are $4 \mu \mathrm{m}, 500 \mathrm{~nm}$, and $100 \mu \mathrm{m}$, respectively, which is the same with $\mathrm{Cu}$ interconnect patterns. $\mathrm{Cu} / \mathrm{Si}_{3} \mathrm{~N}_{4}$ and $\mathrm{Cu} / \mathrm{N}$-graphene interconnect with the damascene-patterned structure were fabricated by formation of $\mathrm{Si}_{3} \mathrm{~N}_{4}$ and $\mathrm{N}$-doped graphene films on damascene patterned $\mathrm{Cu}$ interconnect.

\section{Characterizations}

The surface morphology, quality, uniformity and layers of graphene were characterized by optical microscopy (BX51, Olympus) and FESEM (JSM$7500 \mathrm{~F}, \mathrm{JEOL}$ ). Raman spectroscopy (HR-320, $144 \mathrm{~mW}, \lambda=532 \mathrm{~nm}$, Horiba Jovin-Yvon). Estimations of the atomic compositions of the samples were obtained HRTEM images and EELS mapping in an image-aberrationcorrected TEM (TITAN G2 60-300, FEI). XPS (AXIS Ultra DLD, Kratos Analytical) measurements were carried out using a monochromatic $\mathrm{Al} \mathrm{Ka}$ $\mathrm{X}$-ray source $(1486.6 \mathrm{eV})$ to determine the chemical compositions and work function of the pristine and $\mathrm{N}$-doped graphene films grown on Cu foil. The crystallinity of the Cu foils was evaluated by XRD (D/Max-2500, Rigaku). The electrical properties of interconnect were studied in air at room temperature using a high current source meter (Keithley 2430). The breakdown current density and resistivity of interconnects were estimated from $I-V$ characteristic. The MTTF property was measured at $100^{\circ} \mathrm{C}$ under continuous DC stress of 3 and $10 \mathrm{MAcm}^{-2}$.

\section{DATA AVAILABILITY}

The data that support the findings of this study are available from the corresponding author upon reasonable request.

Received: 18 July 2020; Accepted: 9 March 2021; Published online: 12 April 2021

\section{REFERENCES}

1. Baklanov, M. R., Adelmann, C., Zhao, L. \& Gendta, S. D. Advanced interconnects: materials, processing, and reliability. ECS J. Solid State Sci. Technol. 4, Y1-Y4 (2015).

2. Henriquez, L. et al. Size effects in thin gold films: discrimination between electron-surface an electron-grain boundary scattering by measuring the Hall effect at 4K. Appl. Phys. Lett. 102, 051608 (2015).

3. Khoo, K., Tashiro, S. \& Onuki, J. Influence on the electro-migration resistance by line width and average grain size along the longitudinal direction of very narrow Cu wires. Mater. Trans. 51, 1183-1187 (2010).

4. Behnam, A. et al. Transport in nanoribbon interconnects obtained from graphene grown by chemical vapor deposition. Nano Lett. 12, 4424-4430 (2012).

5. Kang, C. G. et al. Enhanced current drivability of CVD graphene interconnect in oxygen-deficient environment. IEEE Electron Dev. Lett. 32, 1591-1593 (2011).

6. Murali, R., Yang, Y., Brenner, K., Beck, T. \& Meindl, J. D. Breakdown current density of graphene nanoribbons. Appl. Phys. Lett. 94, 243114 (2009).

7. Shao, Q., Liu, G., Teweldebrhan, D. \& Balandin, A. A. High-temperature quenching of electrical resistance in graphene interconnects. Appl. Phys. Lett. 92, 202108 (2008).

8. Jiang, J. et al. Intercalation doped multilayer-graphene-nanoribbons for nextgeneration interconnects. Nano Lett. 17, 1482-1488 (2017).

9. Jiang, J., Chu, J. H. \& Banerjee, K. CMOS-compatible doped-multilayer graphene interconnects for next-generation VLSI. In IEEE Int. Electron Devices Meeting 34.5.1-34.5.4 (2018).

10. Yeh, C. H. et al. Scalable graphite/copper bishell composite for high-performance interconnects. ACS Nano 8, 275-282 (2014).

11. Mehta, R., Chugh, S. \& Chen, Z. Enhanced electrical and thermal conduction in graphene-encapsulated copper nanowires. Nano Lett. 15, 2024-2030 (2015). 
12. Li, L. et al. BEOL compatible graphene/Cu with improved electromigration lifetime for future interconnects. In IEEE Int. Electron Devices Meeting 9.5.1-9.5.4 (2016).

13. Jang, J. et al. Low-temperature-grown continuous graphene films from benzene by chemical vapor deposition at ambient pressure. Sci. Rep. 5, 17955 (2015).

14. Son, M. et al. High-quality nitrogen-doped graphene films synthesized from pyridine via two-step chemical vapor deposition. Carbon 159, 579-585 (2015).

15. Dresselhaus, M. S., Jorio, A., Hofmann, M., Dresselhaus, G. \& Saito, R. Perspectives on carbon nanotubes and graphene Raman spectroscopy. Nano Lett. 10, 751-758 (2010).

16. Wood, J. D., Schmucker, S. W., Lyons, A. S., Pop, E. \& Lyding, J. W. Effects of polycrystalline $\mathrm{Cu}$ substrate on graphene growth by chemical vapor deposition. Nano Lett. 11, 4547-4554 (2011).

17. $\mathrm{Li}$, J. et al. Controllable atmospheric pressure growth of mono-layer, bi-layer and tri-layer graphene. Chem. Commun. 50, 11012-11015 (2014).

18. Li, X. et al. Large-area synthesis of high-quality and uniform graphene films on copper foils. Science 324, 1312-1314 (2009).

19. Han, G. H. et al. Influence of copper morphology in forming nucleation seeds for graphene growth. Nano Lett. 11, 4144-4148 (2011).

20. Capasso, A. et al. Nitrogen-doped graphene films from chemical vapor deposition of pyridine: influence of process parameters on the electrical and optical properties. Beilstein J. Nanotechnol. 6, 2028-2038 (2015).

21. Xue, Y. et al. Low temperature growth of highly nitrogen-doped single crystal graphene arrays by chemical vapor deposition. J. Am. Chem. Soc. 134 11060-11063 (2012).

22. Das, A. et al. Monitoring dopants by Raman scattering in an electrochemically top-gated graphene transistor. Nat. Nanotechnol. 3, 210-215 (2008).

23. Son, J. G. et al. Sub-10 nm graphene nanoribbon array field-effect transistors fabricated by block copolymer lithography. Adv. Mater. 25, 4723-4728 (2013).

24. Kang, C. G. et al. Effects of multi-layer graphene capping on $\mathrm{Cu}$ interconnects. Nanotechnology 24, 115707 (2013).

25. Jiang, J., Parto, K., Cao, W. \& Banerjee, K. Ultimate monolithic-3D integration with 2D materials: rationale, prospects, and challenges. IEEE J. Electron Dev. Soc 7, 878-887 (2019).

26. Wei, F. L. et al. Electromigration-induced extrusion failures in $\mathrm{Cu} / \mathrm{low}-\mathrm{k}$ interconnects. J. Appl. Phys. 104, 023529 (2008).

27. $\mathrm{Hu}, \mathrm{C}$. K. et al. Reduced electromigration of $\mathrm{Cu}$ wires by surface coating. Appl. Phys. Lett. 81, 1782 (2002).

28. Cho, C. et al. Pulsed KrF laser-assisted direct deposition of graphitic capping layer for Cu interconnect. Carbon 123, 307-310 (2017).

29. Vairagar, A. V. et al. Improvement of electromigration lifetime of submicrometer dual-damascene $\mathrm{Cu}$ interconnects through surface engineering. ECS. J. Electrochem. Soc. 153, G840-G845 (2006).

30. Lee, S. K., Hsu, H. C. \& Tuan, W. H. Oxidation behavior of copper at a temperature below $300^{\circ} \mathrm{C}$ and the methodology for passivation. Mater. Res. 19, 51-56 (2016).

31. Lee, C., Wei, X., Kysar, J. W. \& Hone, J. Measurement of the elastic properties and intrinsic strength of monolayer graphene. Science 321, 385-388 (2008).

32. Balandin, A. A. et al. Superior thermal conductivity of single-layer graphene. Nano Lett. 8, 902-907 (2008).

\section{ACKNOWLEDGEMENTS}

This research was supported by the National Research Foundation (NRF) of Korea funded by the Ministry of Science \& ICT (2020R1F1A1069342), Nano-Material
Technology Development Program through the National Research Foundation of Korea (NRF) funded by the Ministry of Science, ICT and Future Planning (2016M3A7B4909942 and 2016M3A7B4900135), Industrial Strategic Technology Development Program funded By the Ministry of Trade, Industry \& Energy (MOTIE, Korea) (10052853) and GIST Research Institute (GRI) grant funded by the GIST in 2021.

\section{AUTHOR CONTRIBUTIONS}

M.S. and J.J. contributed equally. M.S. and M.H.H. conceived and designed the research. M.S. and J.J. performed most of the experiments including graphene synthesis, interconnect fabrication, characterization, and data analysis. J.J. and M.H.H. performed the optical, SEM, and Raman analysis. J.N. and J.Y.H. performed TEM analysis. Y.S. and B.H.L. performed the electrical characteristic measurements. M.S. wrote the manuscript. All authors discussed the results and commented on the manuscript.

\section{COMPETING INTERESTS}

The authors declare no competing interests.

\section{ADDITIONAL INFORMATION}

Supplementary information The online version contains supplementary material available at https://doi.org/10.1038/s41699-021-00216-1.

Correspondence and requests for materials should be addressed to M.S. or S.-S.C.

Reprints and permission information is available at http://www.nature.com/ reprints

Publisher's note Springer Nature remains neutral with regard to jurisdictional claims in published maps and institutional affiliations.

\begin{abstract}
Open Access This article is licensed under a Creative Commons Attribution 4.0 International License, which permits use, sharing, adaptation, distribution and reproduction in any medium or format, as long as you give appropriate credit to the original author(s) and the source, provide a link to the Creative Commons license, and indicate if changes were made. The images or other third party material in this article are included in the article's Creative Commons license, unless indicated otherwise in a credit line to the material. If material is not included in the article's Creative Commons license and your intended use is not permitted by statutory regulation or exceeds the permitted use, you will need to obtain permission directly from the copyright holder. To view a copy of this license, visit http://creativecommons. org/licenses/by/4.0/.
\end{abstract}

(c) The Author(s) 2021 